\title{
Random vibration analysis of an offshore flexible direct current converter valve
}

\author{
Wei Lv ${ }^{1 *}$, Zhiyun Mao ${ }^{2}$ and Lihong Zhang ${ }^{1}$ \\ ${ }^{1}$ China Institute of Water Resources and Hydropower Research, Beijing, 100048, China \\ ${ }^{2}$ Xuji Group Corporration, Xuchang, Henan, 461000, China
}

\begin{abstract}
With the rapid development of the direct-current grid technology and construction, the flexible direct-current transmission technology has been widely used in many aspects, such as long-distance largecapacity power transmissions, offshore platforms and island power supplies. The offshore flexible direct current converter valve will encounter a variety of unfavorable loads during the marine transportation and the long-term operation on the sea. The safety requirements of the offshore flexible direct current converter valve are higher as a result. Based on the structural characteristics of the converter valve, the converter valve is calculated by finite element method. Under two working conditions of the marine transportation and the longterm operation on the sea, this paper carries out modal analysis and random vibration analysis of the converter valve tower respectively. This paper gives the unfavorable position of the force from the calculation results, and provides a reference for the design and selection of the flexible direct current converter valve to meet the needs of the offshore converter station's construction.
\end{abstract}

\section{Introduction}

Compared with traditional DC transmission, flexible DC transmission technology has many advantages, such as the independent control of active and reactive power, low requirements for $\mathrm{AC}$ systems, 4-quadrant operations, passive network power supplies, and smaller floor spaces[1]. Flexible DC transmission technology has longdistance power transmission capabilities. It has flexible active and reactive power control capabilities, too. Flexible DC transmission technology increases power supply reliability and operational flexibility, and has obvious advantages when used for offshore platform power supply[2]. The construction costs and technical difficulties of offshore converter stations are high. There are high requirements for the selection and layout of key electrical equipment of electrical equipment [3-4]. Flexible DC transmission technology has been widely applied at home and abroad. Large-scale offshore wind power transmission projects based on flexible DC transmission technology have become a hot spot for offshore wind power development, and it has also become the focus of research scholars in related fields[5].

The offshore flexible converter station and converter valve may encounter a variety of unfavorable loads during marine transportation and long-term operation on the sea, which is more complicated than the environment faced on land. The converter valve is the key electrical equipment of offshore flexible DC transmission system. As a result, the safety requirements of the offshore flexible direct current converter valve is higher than other equipments.
The offshore platform on which the converter valve is located is subject to dynamic forces during heave, roll and pitch. During the long-term operation, the sustained wave force impacts the platform. As a result, the platform transmits the excitation to the converter valve foundation, so the converter valve is easy to generate vibration, which may cause failure. These vibrations not only affect the normal operation of the converter valve, but also increase the fatigue load of the components, and even shorten the service life of the equipment. Ensuring the safety and integrity of the flexible converter valve tower in marine transportation and long-term operation on the sea is the key to ensuring the safe and efficient operation of flexible DC transmission projects.

In order to study the dynamic response of the offshore flexible DC converter valve during marine transportation and long-term operation on the sea, this paper creates a finite element model based on the structural characteristics of the flexible DC converter valve. For the loads encountered in the above two working conditions, different acceleration power spectral densities are obtained as input conditions, and the modal analysis and random vibration analysis of the converter valve tower are carried out respectively.

\section{The converter valve tower and model parameters}

The research object of this paper is the offshore flexible direct current converter valve. The converter valve consists of four layers of components, and its total weight is about 67 tons. The size of the valve tower is $8.9 \mathrm{~m}$ in

*Corresponding author's e-mail: lvw@iwhr.com 
length, $5.2 \mathrm{~m}$ in width and $11.7 \mathrm{~m}$ in height. The supporting insulators and cable-stayed insulators, which located at the bottom and the interlayer of the valve tower form a staggered network. Among these insulators, cable-stayed insulators of the bottom and the interlayer can only withstand tension but not pressure.

When the converter valve is calculated by finite element method, the beam elements are used to simulate the supporting insulators, component beams, connecting aluminum bars and other components, and nonlinear springs are used to simulate cable-stayed insulators. The converter valve is connected to the platform through the cable-stayed insulators and support insulators at the bottom. The calculation models and boundary conditions are different in these two working conditions.

When the converter valve is in the state of marine transportation, in addition to the bottom support insulators, the converter valve adds some outward cable-stayed insulators to connect with the platform. These reinforcement measures ensure the safety of the converter valve during marine transportation [6-7]. Figure 1 shows the finite element model of the first working condition.

When the converter valve is in a state of long-term operation on the sea, the bottom supporting insulators are directly connected to the platform. Figure 2 shows the finite element model of the second working condition.

Fing
Figure 1. The finite element model of the first working
condition

The material parameters of the main components in the converter valve are shown in Table 1.

Table 1. Material properties of the main components.

\begin{tabular}{ccccc}
\hline Material Name & $\begin{array}{c}\text { Elastic modulus } \\
(\mathrm{GPa})\end{array}$ & Poisson's ratio & $\begin{array}{c}\text { Density } \\
\left(\mathrm{kg} / \mathrm{m}^{3}\right)\end{array}$ & $\begin{array}{c}\text { Allowable stress } \\
(\mathrm{MPa})\end{array}$ \\
\hline Aluminum beam & 71 & 0.34 & 2800 & 270 \\
Insulation beam & 17.6 & 0.34 & 2000 & 100 \\
Cable-stayed insulator & 25 & 0.34 & 1800 & 550 \\
Support insulator & 25 & 0.34 & 1800 & 155 \\
Cast aluminum & 69 & 0.34 & 2700 & 205 \\
Cast steel & 154 & 0.3 & 7800 & 350 \\
\hline
\end{tabular}

\section{Random vibration analysis}

In this paper, different PSD curves are used to analyze the random vibration of the converter valve tower under the working conditions of marine transportation and longterm operation on the sea. Taking the acceleration PSD curve of the platform foundation floor acting on the bottom support structure of the converter valve as the input condition, the random vibration analysis of the converter valve is carried out. In the following figures, the $\mathrm{x}$ direction corresponds to the long side of the converter valve, the y direction corresponds to the short side, and the $\mathrm{z}$ direction is the vertical direction.

\subsection{The working condition of marine transport}

In the process of marine transportation, the platform will produce six degrees of freedom movement under the action of wind, waves, swells and other external forces. Three of the sports have the greatest impact on ships in navigation. They are heaving, rolling and pitching[8-9]. In this paper, the effect of these three dynamic force on the converter valve is considered. The acceleration PSD of the first working condition is shown in Figure 3. 


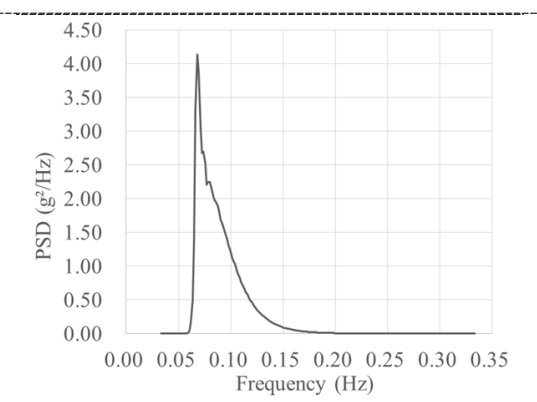

(a) $\mathrm{X}$ direction

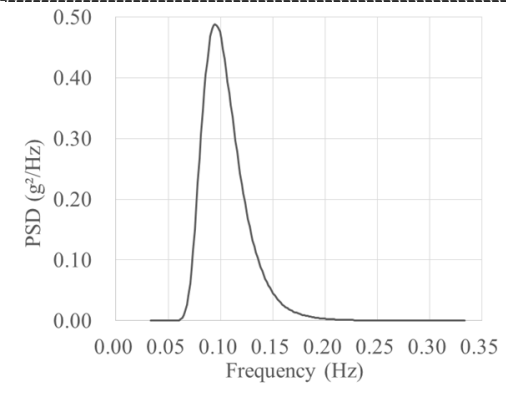

(b) Y direction

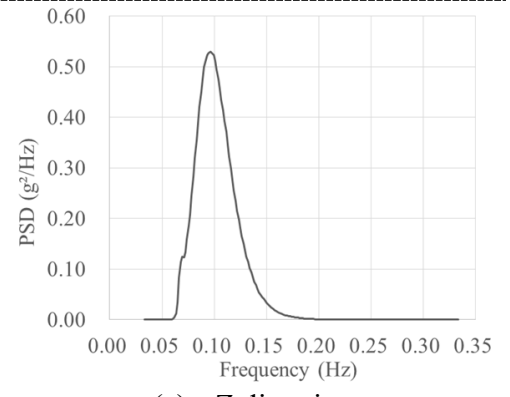

(c) $\mathrm{Z}$ direction

Figure 3. Acceleration PSD of the first working condition

\subsection{The working condition of long-term operation on the sea}

When the converter valve tower is running on an offshore platform for a long time, the wave force impacts the platform and is transmitted to the excitation of the converter valve foundation. The acceleration power spectral density of the second working condition is shown in Figure 4.

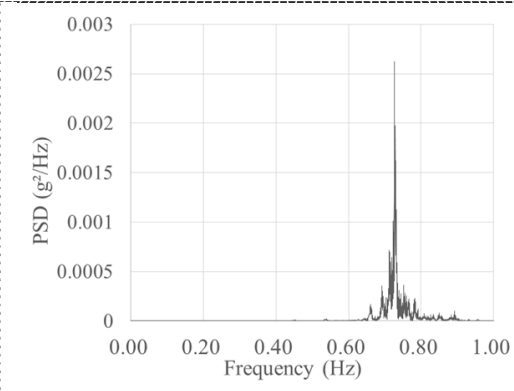

(a) $\mathrm{X}$ direction

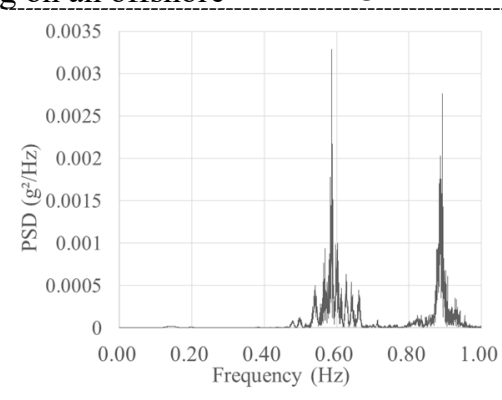

(b) Y direction

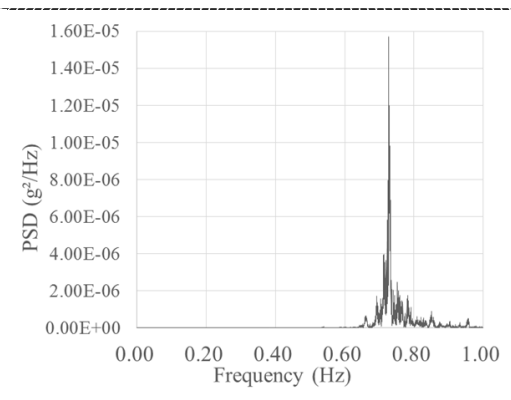

(c) $\mathrm{Z}$ direction

Figure 4. Acceleration PSD of the second working condition

\section{Main contents and results}

\subsection{Results of modal analysis}

From the results of finite element calculation, the first to the tenth natural frequencies of the converter valve are extracted as listed in Table 2. The damping ratio of each mode is set to 0.02 . Compared with the unreinforced valve tower, the fundamental frequency of the reinforced valve tower is significantly increased.

Table 2. Calculation results of natural vibration frequency of valve tower (unit: $\mathrm{Hz}$ ).

\begin{tabular}{ccc}
\hline Mode number & The first working condition & The second working condition \\
\hline 1 & 1.3681 & 0.7085 \\
2 & 1.8173 & 1.2310 \\
3 & 1.8466 & 1.6021 \\
4 & 2.9030 & 2.7306 \\
5 & 5.3753 & 5.1498 \\
6 & 6.8074 & 6.6651 \\
7 & 6.9805 & 6.8402 \\
8 & 8.4180 & 8.2723 \\
9 & 9.7972 & 9.7566 \\
10 & 10.5050 & 10.4760 \\
\hline
\end{tabular}




\subsection{Results of PSD random vibration analysis}

Table. 3 Stress check table for key components of valve tower (unit: MPa)

\begin{tabular}{|c|c|c|c|c|c|}
\hline \multirow{2}{*}{ The name of key components } & \multicolumn{2}{|c|}{ The first working condition } & \multicolumn{2}{|c|}{ The second working condition } & \multirow{2}{*}{ Allowable stress } \\
\hline & $1 \sigma$ & $3 \sigma$ & $1 \sigma$ & $3 \sigma$ & \\
\hline Corona ring & 0.32 & 0.96 & 0.08 & 0.24 & 260 \\
\hline Aluminum beam & 9.84 & 29.52 & 2.49 & 7.47 & 260 \\
\hline Insulation beam & 6.87 & 20.61 & 0.76 & 2.28 & 100 \\
\hline Cast aluminum flange & 49.37 & 148.11 & 59.77 & 179.31 & 205 \\
\hline Cast steel flange & 11.07 & 33.21 & 9.86 & 29.58 & 350 \\
\hline Cable-stayed insulators & 26.02 & 78.05 & 14.24 & 42.71 & 550 \\
\hline Support insulators & 6.71 & 20.13 & 3.94 & 11.82 & 155 \\
\hline
\end{tabular}

According to the principle of Gaussian distribution, the ratio of more than 3 times the root mean square stress is only $0.27 \%$, which is almost negligible. Therefore, this report uses $3 \sigma$ as the peak stress of the random vibration analysis result[10]. Table 3 lists the $1 \sigma$ and $3 \sigma$ stress calculation results of key components. The maximum stress occurs at the position of the cast aluminum adapter flange, and the results show that the $3 \sigma$ value of each component is less than the allowable stress of the material[11], which meets the requirements for strength in the code.

\section{Conclusions}

In this paper, the offshore flexible direct current converter valve is considered the research object, combined with its structural characteristics, the modal analysis and the random vibration analysis of the converter valve tower are carried out. According to the results, the following conclusions can be drawn:

(1) When the flexible direct current converter valve is in the state of marine transportation, appropriate reinforcement measures should be taken. Those measures can effectively increase the fundamental frequency of the converter valve to control the stress value of the components within a safe range. They also ensure the safety of the converter valve's marine transportation and the integrity of equipments.

(2) In the random vibration analysis of the two working conditions, the maximum stress of the component appears at the position of the cast aluminum adapter flange. The results show that the $3 \sigma$ value of each component is less than the allowable stress of the material, and the structural strength of the converter valve meets the requirements of the specification.

(3) This article uses the finite element method to analyze the dynamics of the converter valve of the flexible converter valve. The analysis results include the check of the strength of the structural members and the judgment of the unfavorable position. It can also provide reference for the design optimization and selection of the flexible direct current converter valve.

\section{Acknowledgments}

The authors acknowledge financial supports from the National Natural Science Foundation of China (Grant No.51679265), IWHR Research \& Development Support Program (EB0145B412016).

\section{References}

1. MA, W.M. WU, F.J. YANG, Y.M. et al.(2014) Flexible HVDC transmission technology's today and tomorrow [J]. High Voltage Engineering, 40(8) :24292439.

2. TANG, G.F. HE, Z.Y. PANG, H.(2013) Research, application and development of VSC-HVDC engineering technology $[\mathrm{J}]$. Automation of Electric Power Systems, 37(15) : 3-14.

3. HAO, W.H.(2017) Research on VSC-HVDC converter station application on offshore platform [J]. Southern Energy Construction, 4( 1) : 66-70.

4. HAO, W.H. ZHOU, Y. (2019) Research on the selection of key electrical equipments in offshore VSC-HVDC converter station[J]. Southern Energy Construction, 6(1): 31-35.

5. LIU, W.D. LI, Q.N. WANG, X. et al. (2020) Application status and prospect of VSC-HVDC technology for large-scale offshore wind farms [J]. Electric Power, 53(7):55-71.

6. LI,J. CHEN, J.Y. SUN, Z. (2017)Optimization of fastening measures for transformer marine transportation $[\mathrm{J}]$. Journal of Dalian Maritime University, 43 ( 1 ) : 19-23.

7. Lan, D.N. XU, Q. CHEN, J.Y. et al. (2020)Reinforcement measures of offshore flexible direct current converter valve during marine transportation $[\mathrm{J}]$. Journal of Dalian Maritime University, 46(02):10-16.

8. WEI, Y.Z. (1996)Reinforcement and lashing of heavy goods during ocean shipping $[\mathrm{J}]$. Modern Inspection Technology, (3): 36-39.

9. SUN, L.N. (2006)Safety analyze of large goods transport on the sea[D]. Dalian University of 
Technology, Dalian.

10. Standardization Administration of China. (2018) GB/T2423.56-2018. Environmental testing-part 2: Test Methods-Test Fh: Vibration, broadband random and guidance. China Standard Press, Beijing.

11. Ministry of Construction of China. (2013) GB502602013 Code for seismic design of electrical installation. China Planning Press, Beijing. 